\title{
Efectividad de los Beneficios Administrativos y Judiciales en el Establecimiento Penitenciario y Carcelario de Mediana Seguridad de Neiva entre los años 2012 a $2014^{1}$
}

\section{Effectiveness of Administrative and Judicial Benefits in the Penitentiary and Prison Medium Security of the Neiva between 2012 to 2014}

\section{RESUMEN}

Con el ánimo de fortalecer el cumplimiento de la Misión que tiene la Universidad como institución académica, así como con el propósito de contribuir con las políticas del Estado en materia penitenciaria y carcelaria, se plantea el presente artículo producto de un trabajo conjunto con el Establecimiento Penitenciario de Mediana Seguridad y Carcelario de Neiva (EPMSC-de Neiva), el cual busca analizar la efectividad y el contexto en el que se han desarrollado los beneficios administrativos y judiciales a los que tienen derecho la población carcelaria, y el impacto de dichos dispositivos en la dinámica penitenciaria y social en contexto. Esto implica un análisis jurídico de los beneficios, las solicitudes de sus beneficiarios y la interpretación y aplicación por parte de los Jueces de Ejecución de Penas y Medidas de Seguridad. De igual manera, se abordará el conocimiento que tienen los reclusos de estos beneficios, el debido proceso en cada una de las etapas de las peticiones y las causas para la concesión o no de los mismos. Es de resaltar que esta investigación reviste una cardinal pertinencia de cara a la actual problemática de hacinamiento carcelario que padece el País, puesto que dentro de los propósitos que inspiran estos instrumentos jurídicos, se encuentra establecido que sirven de medida a priori para descongestionar los centros de reclusión, además de ser herramientas que deben estar diseñadas dentro de estrategias de resocialización, propio de un tratamiento penitenciario al que deben someterse los reclusos antes de lograr su libertad y reinserción en la sociedad.

1 El presente artículo, constituye el resultado de la investigación denominada: «Efectividad de los Beneficios Administrativos y Judiciales en el Establecimiento Penitenciario y Carcelario de Mediana Seguridad de Neiva entre los años 2012 a 2014», realizada en el año 2014 por el Semillero de Investigación «IUS EX NUNC», Grupo Conciencia Jurídica, de la Universidad Surcolombiana integrado por los estudiantes: Ingrid Katherinne Caviedes Páez, Astrid Yesenia Rivera Cardozo, María Daniela Gómez Polo, Edwin Andrés García Amaya, Estudiantes de Derecho de la Universidad Surcolombiana. 


\section{PALABRAS CLAVE}

Población carcelaria, beneficios administrativos y judiciales, Centros Penitenciarios y Carcelarios, Juez de Ejecución de Penas y Medidas de Seguridad.

\section{ABSTRACT}

In an effort to strengthen the fulfillment of the mission that the university as an academic institution, as well as the purpose of contributing to state policies in prisons and jails matter herein product of joint work poses with the Establishment Medium Security prison and Prison Neiva (EPMSC - of Neiva), which seeks to analyze the effectiveness and the context in which they have developed administrative and judicial benefits they are entitled to the prison population, and the impact of such devices in the prison context and social dynamics. This involves a legal analysis of the benefits, applications of the beneficiaries and the interpretation and application by the Judges of Executions of Grief and Safety Measure. Similarly, the knowledge among inmates of these benefits will be addressed, due process at each stage of the requests and the reasons for granting or not these benefits. It is noteworthy that this research is of cardinal relevance in view of the current problem of prison overcrowding suffered by the country, since within the purposes that inspire these legal instruments is established that the same I serve as a measure a priori to decongest the centers imprisonment, besides being tools should be designed within resocialization strategies, typical of a correctional treatment that prisoners must undergo before leaving and returning to the community.

\section{KEYWORDS}

Prison population, administrative and judicial benefits, Corrections and Prisons, Judge of Execution of Sentences and Security Measures.

\section{INTRODUCCIÓN}

El Semillero de Investigación IUS EXT NUNC, planteó como objetivo desarrollar la investigación denominada «Efectividad de los Beneficios Administrativos y Judiciales, en el Establecimiento Penitenciario y Carcelario de Mediana Seguridad de Neiva entre los Años 2012 a 2014», nace como una de las iniciativas al interior del proyecto de Proyección Social del Programa de Derecho de la Universidad Surcolombiana, denominado «Recurso Ama-Gi», el cual tiene por objeto proporcionar ayuda jurídico-social a la población reclusa del establecimiento penitenciario de Neiva, en cuanto a suministrar asesoría para la obtención de beneficios administrativos y subrogados penales, así como el estudio de casos de reclusos inocentes que por determinadas circunstancias fueron injustamente condenados y la implementación de un programa de educación no formal para la resocialización y el desarrollo humano.
El problema de la investigación se orientó a determinar la efectividad de los beneficios administrativos y judiciales en el Establecimiento Penitenciario de Neiva, realizando para el efecto una caracterización y definición de cada uno de los mismos, frente a los fines teóricos de las penas, los cuales son: i). Prevención general; ii). Retribución justa; iii). Prevención especial; iv). Reinserción social; y v). Protección al condenado. Se destaca para el caso particular las de reinserción social y protección al condenado, las cuales imponen la garantía de la vigencia de los derechos fundamentales de los internos, y su derecho a ser preparado para la resocialización y posterior reingreso a la vida en libertad, es decir, la pena tiene funciones protectora y preventiva, pero su fin fundamental es la resocialización.

Se quiso abordar la situación de los Centros de Reclusión, en atención a que existen serios indicios que señalan que estos se han convertido en verdaderos focos de delincuencia y reproducción 
de conductas abyectas, sitiados por el abandono estatal, el hacinamiento, la tensión interna, la comisión de intra-delitos y el desconocimiento de los derechos humanos. Empero, retomando la esencia que inspira el sistema, su carácter resocializador, puede vislumbrarse entre otros, en los beneficios administrativos y judiciales, como un instrumento pedagógico que acerque a los reclusos con su familia y con la sociedad, pero bajo determinadas condiciones, como parte de un proceso de acercamiento y de reconocimiento de las consecuencias de la infracción de las reglas sociales jurídicamente establecidas.

Esto implica que el proyecto aborde en sus objetivos el análisis del impacto y desarrollo de estos beneficios, determinando sí se ha cumplido o no su finalidad, lo que incluye indagar sobre su difusión entre la población carcelaria, el papel del establecimiento penitenciario y la interpretación por parte de los jueces de ejecución de penas, quienes en ultimas aplican estas disposiciones.

En principio, la investigación se desarrolló con un enfoque cualitativo, consistente en el análisis e interpretación de la Constitución, las Leyes, Códigos y Jurisprudencia, en lo atinente a la definición, delimitación y alcance de lo que jurídicamente en Colombia debe entenderse por beneficios administrativos y judiciales en materia penitenciaria y carcelaria. No obstante, la investigación igualmente conjuga un enfoque cuantitativo, conforme a unos instrumentos diseñados por el Semillero a fin de determinar la efectividad de los beneficios administrativos y judiciales.

Conforme a lo anterior, se recurrió al método sistemático, con el fin de analizar las normas contentivas de los beneficios administrativos en consonancia con la Constitución y el Bloque de Constitucionalidad. También se utilizó el método sociológico, que va de la mano con el anterior, puesto que consiste en comparar lo que dice la norma (previo análisis de la misma) con la realidad que se vive al interior del Centro Penitenciario, es con este método que se pretende realizar la recolección de datos relevantes para la investigación.
Finalmente, para el desarrollo del método, se emplearon instrumentos para entrevistas, los cuales se aplicaron a los Jueces de Ejecución de Penas y Medidas de Seguridad de Neiva y al Director del Establecimiento Penitenciario y Carcelario de Neiva, con el fin de conocer su perspectiva frente al objeto de la investigación realizada. Así mismo, se utilizó un instrumento consistente en una encuesta para la población reclusa, con el propósito de contemplar la situación desde su punto de vista, en la cual se indagó acerca del grado de conocimiento de los siguientes aspectos: conocimiento de los beneficios, solicitudes realizadas, la comprensión de los argumentos de las decisiones y el medio por el cual conoció y presentó la solicitud para el beneficio. También se utilizó la encuesta en el análisis de algunos autos proferidos por los Jueces de Ejecución de Penas, a fin de determinar el número de solicitudes que reciben en sus Despachos con relación a la concesión de algún beneficio, los argumentos esbozados por los solicitantes y los mencionados en la decisión, así como conocer sí estas decisiones son objeto de recurso por los interesados.

Es necesario resaltar en primer lugar que para la fecha de la investigación, el Establecimiento Penitenciario de Neiva contaba con una población total de 2.223 reclusos, de los cuales, 1.801 se encontraban físicamente, sea purgando la pena o con detención preventiva, el restante de la población se encontraba disfrutando de algún beneficio judicial o administrativo. Ahora bien, la muestra poblacional de la presente investigación corresponde al $5.5 \%$ del total de reclusos que se encontraban de forma física en el establecimiento penitenciario en mención. Esta muestra corresponde a reclusos hombres de los patios 2A, 2B, 3 y 4, y al pabellón único de mujeres. No se tomó en cuenta al patio $1 \mathrm{~A} Y 1 \mathrm{~B}$, puesto en dichos patios se encuentran personas condenadas por delitos gravosos, lo que ocasiona la exclusión del goce de los beneficios.

Como se señalara anteriormente, se tomó una muestra de los autos proferidos por los cuatro juzgados de Ejecución de Penas y Medidas de Seguridad de Neiva, durante el periodo comprendido entre los años 2012 a 2014, con el fin de 
realizar un ejercicio comparativo con los resultados obtenidos de la encuesta aplicada a la población reclusa.

\section{DESARROLLO DEL TEMA}

Ahora bien, para un apropiado entendimiento del tema resulta necesario establecer de manera puntual, qué son los beneficios administrativos y judiciales y cuándo son procedentes. Respecto al primer aspecto, podría afirmarse que los beneficios son mecanismos de política criminal del Estado, inherentes a la ejecución individual de la condena, que se relacionan con las fases del tratamiento penitenciario. En algunos casos pueden implicar la reducción del tiempo de privación efectiva de la libertad dispuesto en la sentencia, o una modificación en las condiciones de ejecución de la condena. El destinatario principal de los beneficios penitenciarios es el interno recluido en el lugar de ejecución de la condena, así como sus familiares, empero, la misma está igualmente dirigida al colectivo social, en la medida en que la sociedad es receptora del interno. (Castro, 2009).

Los beneficios administrativos se encuentran desarrollados en el Código Penitenciario y Carcelario (Ley 65 de 1993) en sus Artículos 147 a 149, junto con algunas leyes modificatorias, entre los mismos se encuentran: permiso hasta de setenta y dos horas; permiso de salida por 15 días; permiso de salida por fines de semana; libertad preparatoria y franquicia preparatoria, el trabajo extramuros y penitenciaría abierta.

De otra parte, los beneficios judiciales se encuentran consagrados en los Artículos 38, 38B, 38C, 38D, 38E, 38F, 38G, y del 63 al 68 del Código Penal (Ley 599 de 2000) y en los Artículos 465 al 479 del Código de Procedimiento Penal (Ley 906 de 2004), siendo estos: Suspensión Condicional de la ejecución de la pena; libertad condicional; reclusión domiciliaria u hospitalaria por enfermedad muy grave; prisión domiciliaria; prisión domiciliaria para madres o padres cabeza de familia; sistema de vigilancia electrónica; internación del inimputable y libertad vigilada.
En cuanto a los beneficios judiciales, la Ley señala que estos deben ser solicitados ante los Jueces de Ejecución de Penas y Medidas de Seguridad, así mismo, conforme la Sentencia C-312 del año 2002, los Jueces de Ejecuciones de Penas y Medidas de Seguridad deberán aprobar las propuestas de beneficios administrativos que le formulen las autoridades penitenciarias siempre que supongan modificaciones en las condiciones de cumplimiento de la condena o reducciones del tiempo de privación efectiva de la libertad.

Para el otorgamiento de los beneficios, al momento de tomar la decisión, los Jueces tienen en cuenta los siguientes aspectos:

a) Elemento objetivo: el cual versa sobre redención de pena, tener buena conducta al interior del establecimiento penitenciario; no fugas 0 tentativa de ella; haber descontado parte de la condena, esto depende del beneficio, así para que sea concedido algunos de estos beneficios, se exigen el cumplimiento de las $4 / 5$ partes de la pena 0 en otros casos del $70 \%$, dependiendo como tal del beneficio que se solicita; algunos contemplan visto bueno del director del establecimiento penitenciario o director regional del INPEC. Existen también unos beneficios que sólo proceden ante la negatoria de otro, así es el caso de la franquicia preparatoria, la cual es procedente una vez superada la libertad preparatoria y negada la libertad condicional.

b) Elemento subjetivo: exige en primera medida la previa valoración de la conducta punible, es decir, la evaluación que emite el juez de conocimiento al momento de dictar la sentencia. Este aspecto ha sido criticado en cuanto se trata de dejar al «arbitrio del juez» la concesión del beneficio, sin embargo, sobre el mencionado asunto los jueces entrevistados argumentan que en este punto se debe tener en cuenta la mayor intervención que ha tenido el delito en los bienes jurídicos tutelados, se debe analizar también la reincidencia en el delito, además se siguen los criterios dados por la corte constitucional, al igual que la 
protección a la víctima y a la sociedad, la incidencia de la conducta punible, esto es, si causan mayor daño antijurídico y afectan la paz y armonía social, debiendo ser castigados más severamente y su ejecución debe hacerse de tal manera que el victimario padezca los rigores de la pena por el daño causado.

Es de resaltar, que muchos delitos se encuentran excluidos de los beneficios, tal es el caso del permiso de salida por fines de semana, el cual no procede contra los condenados por delitos de terrorismo, secuestro, secuestro extorsivo, extorsión y conexos, según lo establece el Decreto 232 de 2 de febrero de 1998 y la Ley 733 del 2002 en su artículo 11.

Igualmente, sea la oportunidad para señalar que el Artículo 68A de la Ley 599 de 2000, establece la exclusión de los beneficios administrativos y subrogados penales, norma que sí bien es cierto fue modificado por la reforma del 2014, esta tan sólo suprimió el aspecto de los delitos preterintencionales. Empero, la reforma de la Ley 1474 de 2011 y la 1453 de 2011, endurecieron fuertemente la limitación de beneficios, abandonando el concepto de excepcionalidad de la restricción al derecho a la libertad, a manera de ejemplo, excluyendo de manera amplía el número de delitos respecto de los cuales no proceden este tipo de beneficios.

No obstante es de señalarse que la Ley 1709 de 2014 realizó avances a favor de los internos en lo concerniente a medidas que privan la libertad, por ejemplo instituyó que la carencia de recursos económicos para el pago de la multa no puede ser un limitante 0 impedimento para acceder a la libertad, contrario sensu el Juez planteará medidas diferentes para que los internos que no tengan recursos económicos puedan contribuir con trabajo útil a la comunidad. En el mismo sentido, estableció concretamente la prerrogativa de que el brazalete electrónico, en caso que el Juez a su arbitrio lo ordene como medida complementaria para la prisión domiciliaria, y cuando el beneficiario no cuente con la capacidad económica para sufragarlo, el Gobierno estaría en la obligación de suministrarlo.
Pero de dicha legislación, de la cual se esperaba flexibilidad frente al problema del hacinamiento y las dificultades del tratamiento penitenciario, de manera contraria contempló la exclusión de conductas punibles de cualquier subrogado penal, al modificar el artículo 68A de la Ley 599 de 2000 señalando que quienes sean condenados por delitos en contra de la Administración Pública, contra la libertad, integridad y formación sexual, por violencia intrafamiliar, por testaferrato, enriquecimiento ilícito entre otros no tendrán derecho a gozar de ningún beneficio judicial 0 administrativo.

\section{AVANCES, RESULTADOS, DISCUSIÓN}

Teniendo como punto de partida los anteriores aspectos, se hace necesario determinar sí existe y cuál es la efectividad de los beneficios administrativos y judiciales en el Establecimiento Penitenciario y Carcelario de Neiva (EPMSC); para el efecto se analizarán puntos en concreto, lo cual permitirá visualizar de manera detallada los resultados obtenidos en la investigación.

\subsection{Resultados de la encuesta aplicada a los reclusos}

Para la obtención de los resultados que se presentan a continuación, es necesario tener claridad que la muestra está determinada por un total de 100 internos encuestados, los cuales se encontraban al momento de la investigación distribuidos de la siguiente manera dentro del Centro Carcelario:

Pabellón mujeres: 25 Internas, Patio $\mathrm{N}^{\circ}$. 2: 27 internos, Patio $N^{\circ}$. 3: 25 internos, Patio $N^{\circ} .4: 23$ internos. Total de 100 encuestados.

La muestra obtenida estuvo supeditada a la colaboración del EPMSC de Neiva, así como a la cooperación de los reclusos y reclusas.

Gráfica 1. Redención de pena: De los 100 reclusos encuestados, 93 han redimido su pena por trabajo, estudio o enseñanza, ello refleja el conocimiento que sobre el asunto tienen los reclusos. Este punto es importante puesto que tanto la norma que consagra los beneficios administrativos y judiciales, 
Gráfica 1. Redención de pena.

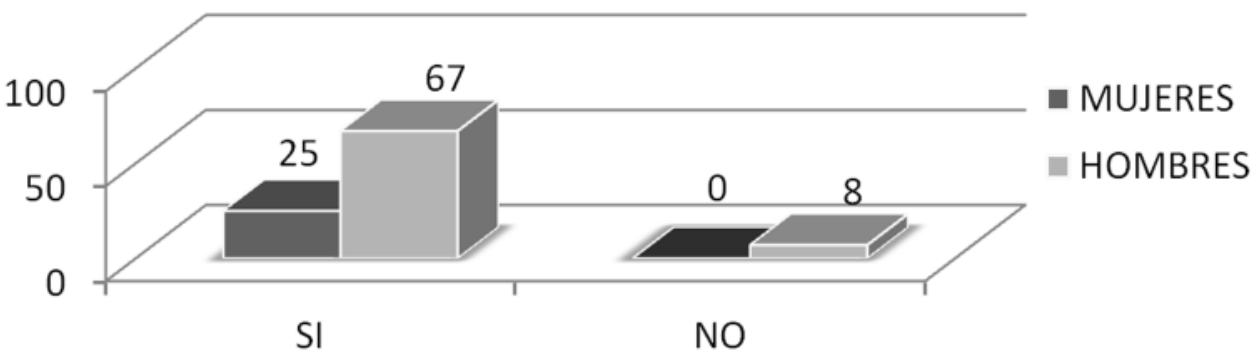

como los jueces que son los encargados de concederlos, hacen énfasis en que el recluso haya redimido pena con los objetivos tanto de descontar pena física, como parte también del tratamiento penitenciario que deben realizar por su paso por el establecimiento penitenciario. Podría concluirse sobre este punto que la aplicación y conocimiento de la norma respecto a la redención está siendo efectiva por el alto porcentaje.

\section{Gráfica 2. Nivel de conocimiento de los beneficios} por parte de los reclusos del EPMSC-de Neiva: A pesar de que la gráfica refleja un alto conocimiento de los internos frente al tema objeto de estudio, es importante resaltar una situación particular que ocurrió al momento de la aplicación del instrumento, al indagar a los encuestados acerca del conocimiento de los beneficios administrativos y judiciales, la mayoría de ellos señalaba no saber sobre el tema o los asimilaban a las fases de tratamiento penitenciario (alta, mediana y baja seguridad) y por tanto, era necesario explicarles a qué se hacía referencia, ante

Gráfica 2. Nivel de conocimiento de los beneficios por parte de los reclusos del EPMSC-de Neiva.

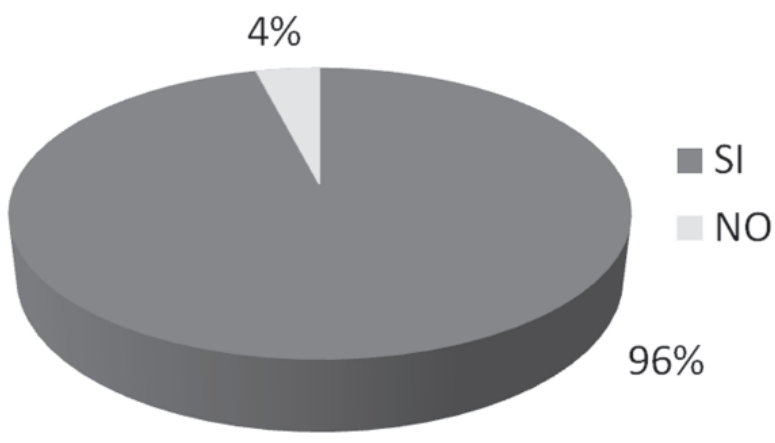

lo cual manifestaban tener una noción de los mismos, obteniendo así los resultados generales anteriores. Es así como desde este punto de partida se ponen de manifiesto las dificultades en cuanto a la publicidad de la normativa y la enseñanza de los beneficios a los cuales pueden acceder los reclusos una vez cumplan los requisitos legales

Gráficas 3, 4 y 5. Clasificación de los Beneficios Administrativos según nivel de conocimiento.

De las anteriores se puede extraer que los reclusos conocen en mayor medida los beneficios administrativos de permiso de hasta 72 horas y el permiso de salida por 15 días, mientras que existe un alto desconocimiento de los demás beneficios, situación más preocupante en el caso de las mujeres.

Tal circunstancia se puso de presente a los Jueces de Ejecución Penas, quienes fueron unánimes al señalar que en tratándose de beneficios administrativos, a excepción del permiso de hasta 72 horas, los demás no son muy solicitados, esto, debido a que en gran parte su concesión está supeditada a la discrecionalidad de las autoridades penitenciarias, del INPEC, quienes en su criterio, son remisas frente al asunto, tal vez por el temor que eventualmente genera el otorgar ese tipo de beneficios y que los reclusos no cumplan con la legalidad y exigencias de aquellos, y, sea este un motivo para que inicien en su contra investigaciones de tipo disciplinaria. Al respecto algunos juzgados señalaron que el permiso de hasta 72 horas el que mayor demanda tiene por parte de los internos, toda vez que exige menos requisitos. Además, expresaron que los Juzgados de Ejecución de Penas y Medidas de Seguridad realizan visitas cada tres meses a la 
Gráfica 3. Total.

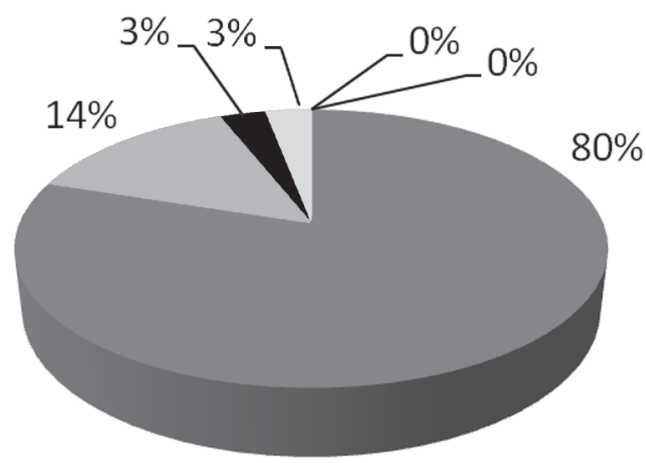
72 horas
15 días
- Franq. Preparatoria
Libert. Preparatoria
Fines de semana
Trab. Extramuros

Gráfica 4. Mujeres.

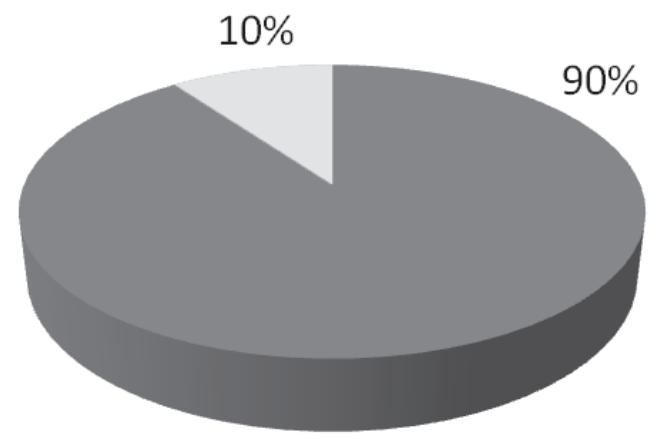

Gráfica 5. Hombres.
A. Permiso 72 horas
B. Permiso de 15 días
C. Franquicia preparatoria
D. Libertad. preparatoria

cárcel. Así mismo señalan que los beneficios judiciales, son sin duda alguna los más solicitados, a diferencia de los administrativos, los cuales un año atrás, solamente era solicitado el permiso de hasta 72 horas, pero ahora se ha venido incrementando el uso de otros como el permiso de 15 días que fue concedido por primera vez en algunos municipios del Departamento del Huila como lo fue en la Plata, luego Pitalito y por último Neiva.

Frente al tema, señaló el Director del Establecimiento Penitenciario de Neiva, que el bajo número de solicitudes diferentes al beneficio de hasta 72 horas, se debe entre otros aspectos, al desconocimiento de la documentación que los internos deben reunir, resaltando además la demora de los entes de seguridad y control para expedir sus certificados como la Sijin, la Dipol, entre otros, aunado a la falta de personal que en ocasiones se presenta para cumplir con los trámites. Finalmente, agregó que el EPMSC de Neiva se dedica solo a enviar los documentos sustento de las peticiones.

Gráficas 6, 7 y 8. Clasificación de los Beneficios Judiciales según nivel de conocimiento.

Respecto a los beneficios judiciales o subrogados penales, de los existentes, tan sólo su conocimiento se limita a cuatro de ellos. Básicamente sucede lo mismo que con los beneficios administrativos, incluso, más allá de lo material, se hicieron evidentes, al momento de la aplicación del instrumento, las imprecisiones conceptuales en lo referente a los beneficios existentes, es 
Gráfica 6. Clasificación de los Beneficios Judiciales según nivel de conocimiento. Consolidado general.

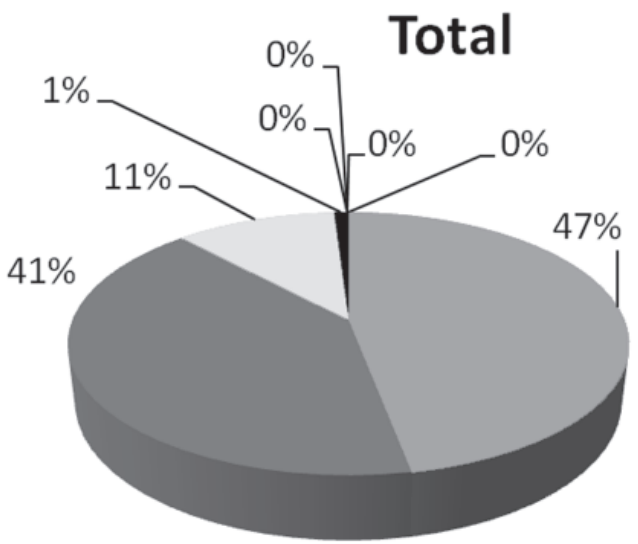

Domiciliaria

Lib. Condicional

Brazalete electrónico

Pris. Domic. Madres C.D.H.

Reclu. Hospitalaria

Suspe. Cond. de Pena.

Inter. Inimputable

Lib. Vigilada

Gráfica 7. Consolidado mujeres.

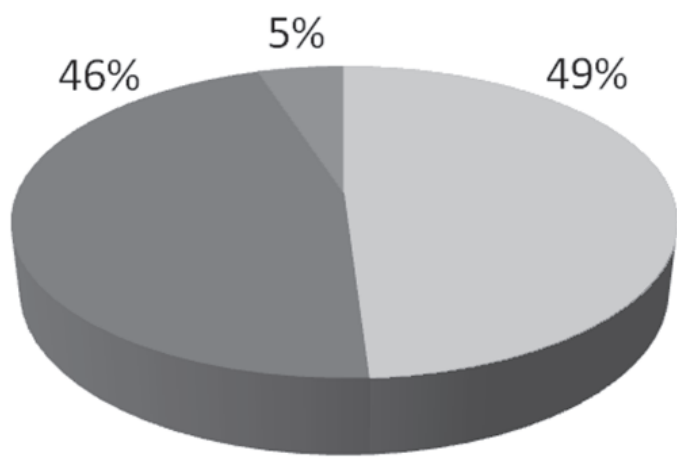

Gráfica 8. Consolidado hombres.

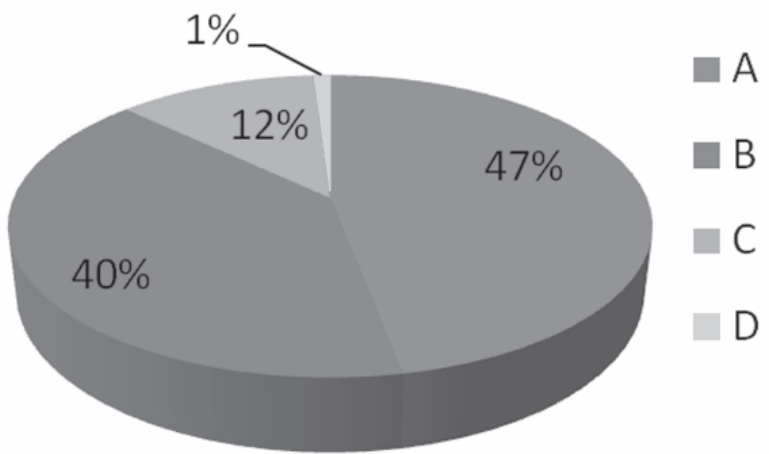
A. Prisión domiciliaria
B. Libertad condicional
C. Brazalete electrónico
D. Madre cabeza hogar.

decir, había confusión entre cuáles era beneficios administrativos y cuáles los judiciales, imprecisión en su definición y desconocimiento de sus procedimientos. Sobre este punto, los Jueces de Ejecución de Penas señalaron que estos beneficios judiciales procuran la resocialización de las personas recluidas en un establecimiento penitenciario y que son medidas alternativas de reclusión, insistiendo en que deberían implementarse más de aquellos. Cabe resaltar la posición de una Juez, quien plantea que faltan programas serios para rehabilitar al delincuente, que no basta tenerlos encerrados en una cárcel o concederles prisión domiciliaria.

Gráfica 9, 10 y 11. Beneficios administrativos solicitados.

Las gráficas 9, 10 y 11, permiten observar cuáles beneficios administrativos son los más solicitados, se enseña que el $95 \%$ de los encuestados han solicitado permiso de hasta 72 horas y tan sólo el $5 \%$ ha pedido otro beneficio, el permiso de 15 días, esto en el caso de los hombres, pero realmente son inexistentes las solicitudes por otro beneficio 
Gráfica 9. Consolidado General beneficios administrativos solicitados.

\section{Total}

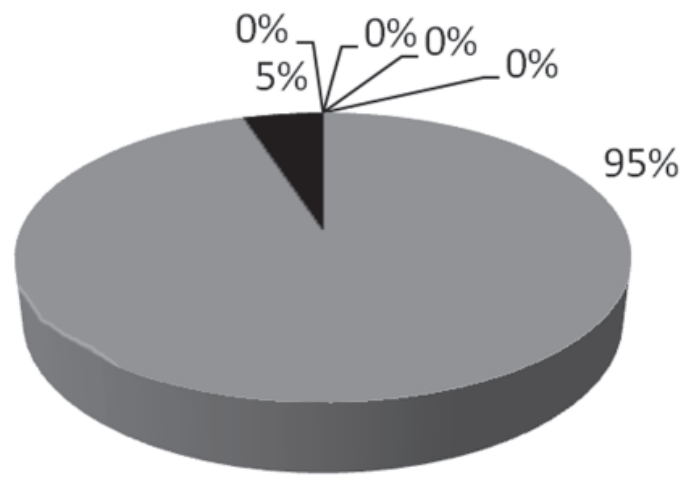

72 horas

15 días

Franq. Preparatoria

Libert. Preparatoria

Fines de semana

Trab. Extramuros

Gráfica 10. Mujeres.

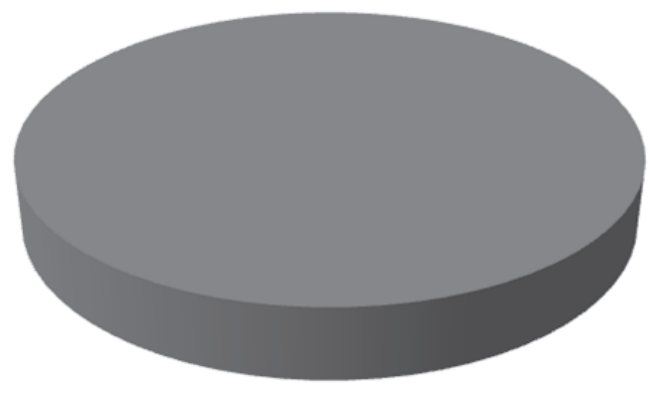

Gráfica 11. Hombres.

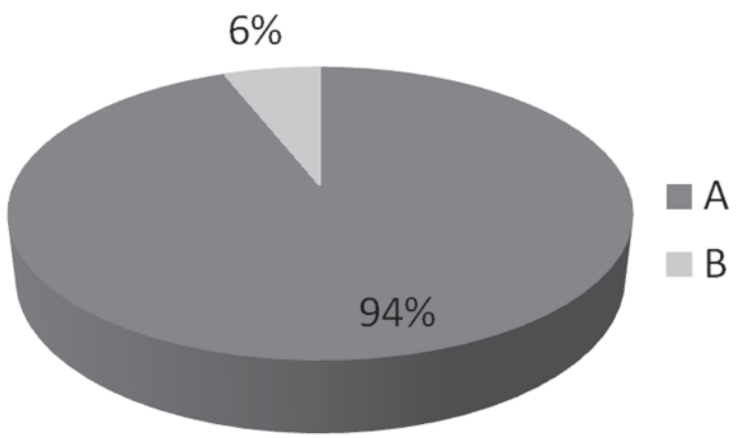

A. Permiso de hasta 72 horas

B. Permiso de 15 días administrativo como franquicia preparatoria, permiso de fines de semana, libertad preparatoria, que existen en el ordenamiento, pero que los reclusos no conocen.

Gráfica 12, 13 y 14. Beneficios judiciales solicitados.

La investigación ha indicado que los tres beneficios judiciales más conocidos, solicitados y de los cuales gozan los privados de la libertad son la prisión domiciliaria, la libertad condicional y el mecanismo de vigilancia electrónica, comúnmente conocido como brazalete electrónico. De esta manera, sí se compara con la gráfica anterior, se puede denotar que los internos conocen y solicitan más los beneficios judiciales, los cuales están contenidos en el Código Penal.

Debe reflexionarse, que si bien es cierto son pocos los beneficios conocidos, estos pocos están siendo solicitados de manera constante y en grandes proporciones a los Jueces de Ejecución de Penas, podría decirse incluso, que esta situación podría obedecer a la flexibilización de algunos de los requisitos, en algunos delitos concretos, que incorporó la reforma penitenciaria y carcelaria, Ley 1709 de 2014, principalmente, la prisión domiciliaria, ya que entre otros, redujo el requisito objetivo de cumplimiento de un tiempo razonable de la pena, consistente en la mitad de la misma. Es más, en la 
Gráfica 12. Total.

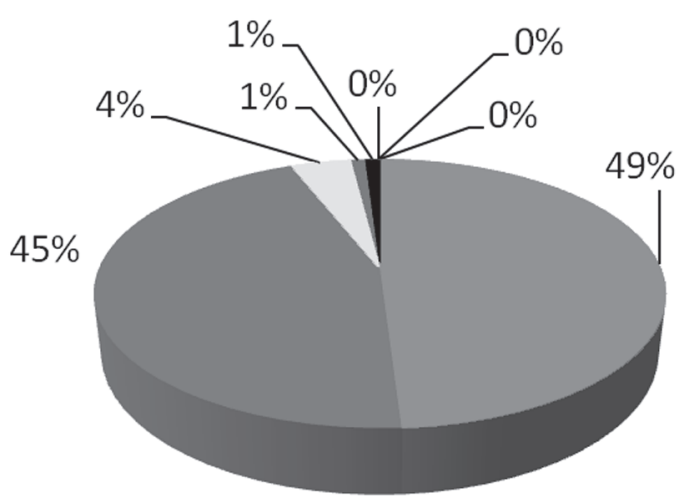

Domiciliaria

Lib. Condicional

Brazalete

Madres cabeza de hogar

Susp. Condicional

Reclu. Hospitalaria

Inter. Inimputable

Lib. Vigilada

Gráfica 13. Mujeres.

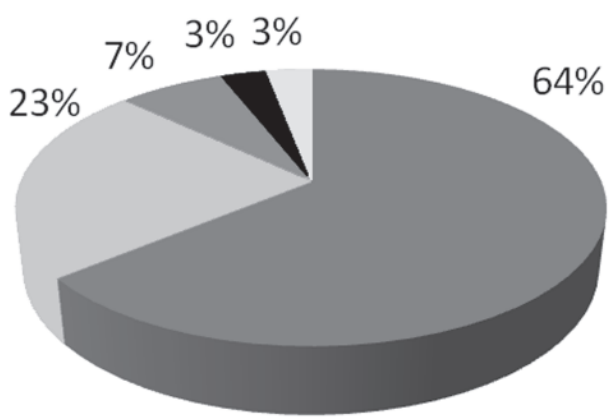

Gráfica 14. Hombres.

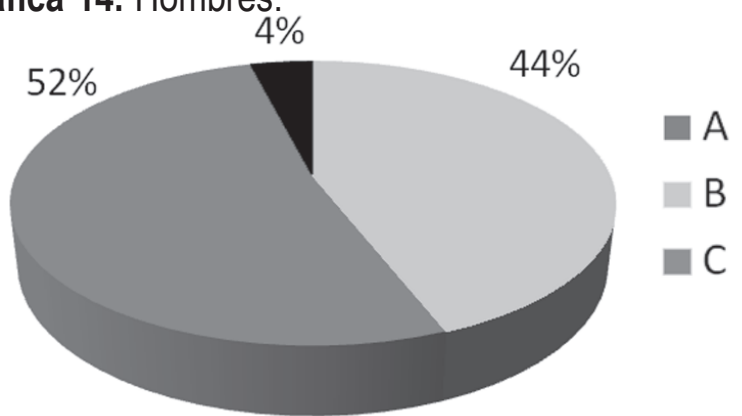
A. Prisión domiciliaria
B. Libertad condicional
C. Brazalete electrónico
D. Suspensión condicional
E. Madre cabeza de hogar.

actualidad son muchos los reclusos condenados que han salido del EPMSC de Neiva en virtud de esta norma, lo que permite confirmar que la reforma fue estatuida con el propósito de contribuir a descongestionar las cárceles y contrarrestar el hacinamiento y las condiciones indignas de los internos, empero, el sistema requiere una reorganización y restructuración, que fortalezca el tratamiento penitenciario mediante estrategias claras de resocialización y prevención del delito, que no existen actualmente en nuestro país.

Es lamentable que la respuesta a la delincuencia como problemática social tan sólo sea la cárcel, como quiera que el INPEC no cuenta con la estructura necesaria para realizar un tratamiento penitenciario que se corresponda con las finalidades de la pena, dentro de las cuales subrayamos concretamente la de resocialización, no sirviendo de nada la implemen- tación de dispositivos sustitutivos de la pena sino se implementan mecanismos que efectivamente redireccionen los proyectos de vida de las personas que equivocadamente toman el rumbo del delito. Es por ello que necesitamos un sistema centrado en la dignidad de la persona y ajustado a los estándares internacionales en la materia, tales como las reglas mínimas para el tratamiento de reclusos (1955) y los principios básicos para el tratamiento de reclusos que prevén condiciones dignas de convivencia, tratamiento enfocado a la reinserción social y a la resocialización y clasificación obligatoria de los privados de la libertad, esto último teniendo en cuenta el enfoque diferencial, aspectos igualmente mencionados por la Corte Constitucional en su jurisprudencia, verbigracia sentencias T-318/1995, T-153/1998, T-1030/2003, entre otras, y que se encuentran dentro del marco del Bloque de Constitucionalidad. 
Gráfica 15 y 16. Beneficios administrativo concedidos y negados.

Gráfica 15. Permiso de hasta 72 horas.

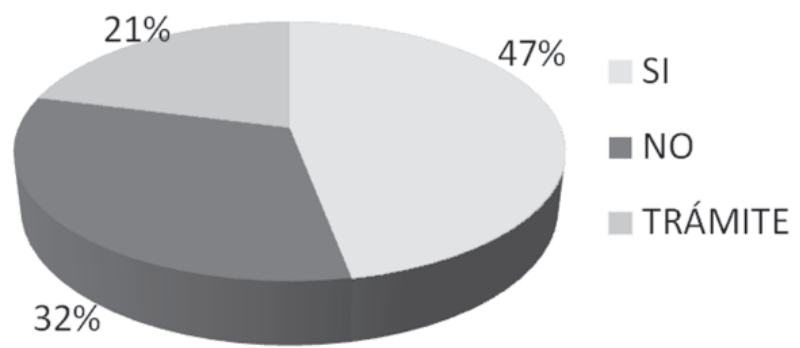

Gráfica 16. Permde salida por 15 días.

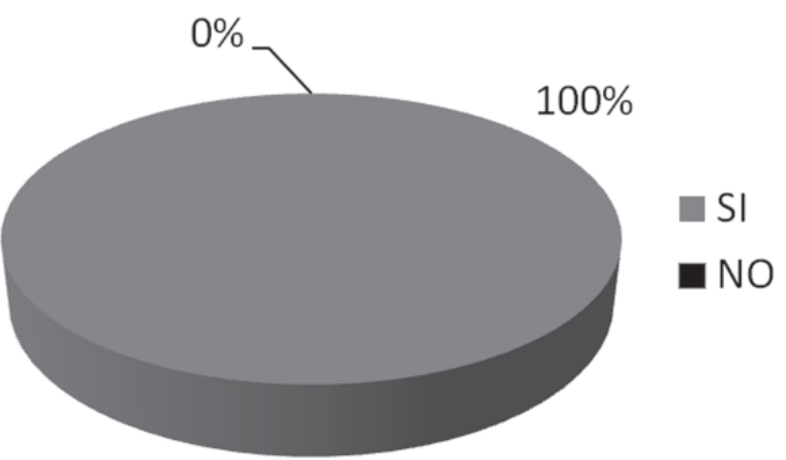

Sigue siendo fundamental el tema de los beneficios administrativos, lastimosamente confundidos, desconocidos, y por ende no solicitados, o si se solicitan y no son concedidos, precisamente por desconocimiento de una norma tan fundamental para la relación de sujeción que tienen con el Estado, como lo es la Ley 65 de 1993, que determina todo lo que atañe al sistema penitenciario y carcelario y que no tiene una estrategia pública de divulgación, afectando fehacientemente los derechos y beneficios de la población carcelaria.

La anterior gráfica refleja que de cada 9 peticiones de permiso de hasta 72 horas, 6 están siendo negadas y tan sólo 3 se están concediendo. Lo que invita a reflexionar sobre lo que sucede al momento de su interposición y las razones de la negativa, aspecto que con alta probabilidad puede estar relacionado con el desconocimiento.

Graficas 17, 18, 19, 20. Beneficios judiciales concedidos y negados.
Gráfica 17. Prisió domiciliaria.

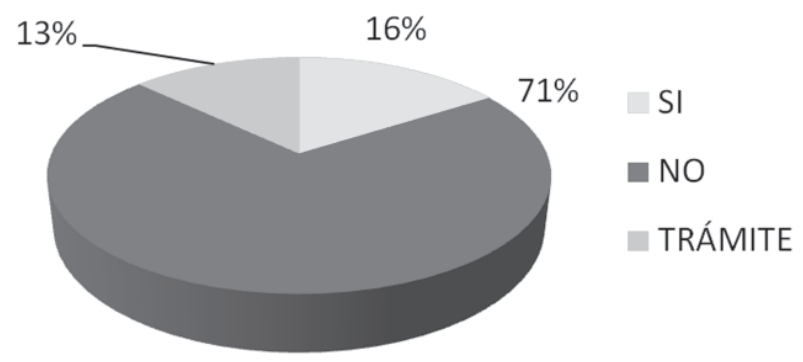

Gráfica 18. Libertad condicional.

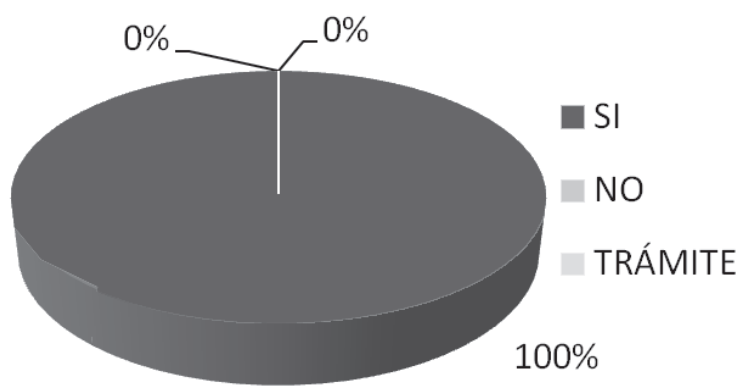

Gráfica 19. Brazalete electrónico.

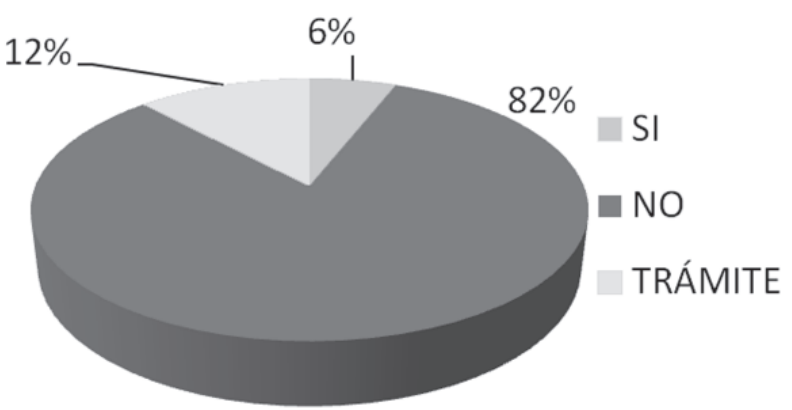

Gráfica 20. Prisión domiciliaria. Madres cabeza...

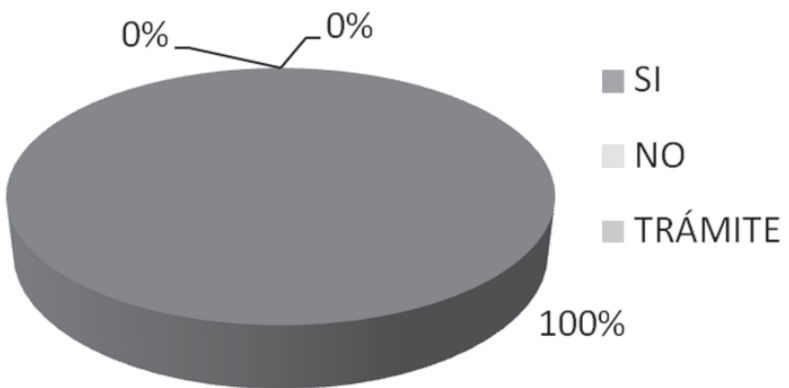

Pese a la implementación de la ley 1709 de 2014, puede verse que la concesión de beneficios sigue siendo muy baja. Puede decirse entonces que a pesar de la reforma, su propósito de incidir en la concesión de beneficios administrativos y judiciales 
como mecanismos para contribuir con el fin de la pena, esto es la resocialización, no se está materializando.

Gráfica 21. Balance de beneficios administrativos concedidos por año.

Gráfica 22. Balance de beneficios judiciales concedidos por año.

De la primera gráfica se observa que no es bueno el balance en tratándose de beneficios administrativos, evidenciándose un bajo número de peticiones. En el año 2012 se presentaron 4 de las cuales se negaron 2 y concedieron 2, en el 2013 fue menor el número de beneficios administrativos concedidos, y en lo corrido del año 2014 hasta la fecha de culminación de la presente investigación, se evidenciaron 4 solicitudes que prosperaron.
Tratándose de beneficios judiciales, el panorama es similar, aunque varía en algunos aspectos. En el 2012 más de la mitad de los que se solicitaron fueron negados. Por su parte en el 2013, 30 de 31 fueron negadas, mientras que en los primeros 3 meses del año 2014, han sido negadas 38 solicitudes y tan sólo 5 fueron concedidas. Sin embargo, coincide el año de la reforma con un aumento en el número de solicitudes presentadas pero sin que signifique necesariamente un aumento en su número de otorgadas.

Gráfica 23. Motivos de la negación del beneficio solicitado.

Tenemos: a). Modalidad de la conducta punible; b). No indemnización de la víctima; c). No es competencia de la autoridad a la que solicito; d). Falta de cumplimiento de requisitos; e). Falta de tratamiento penitenciario; f). Culpa del recluso; g). Desconoce

Gráfica 21. Balance de beneficios administrativos concedidos por año.

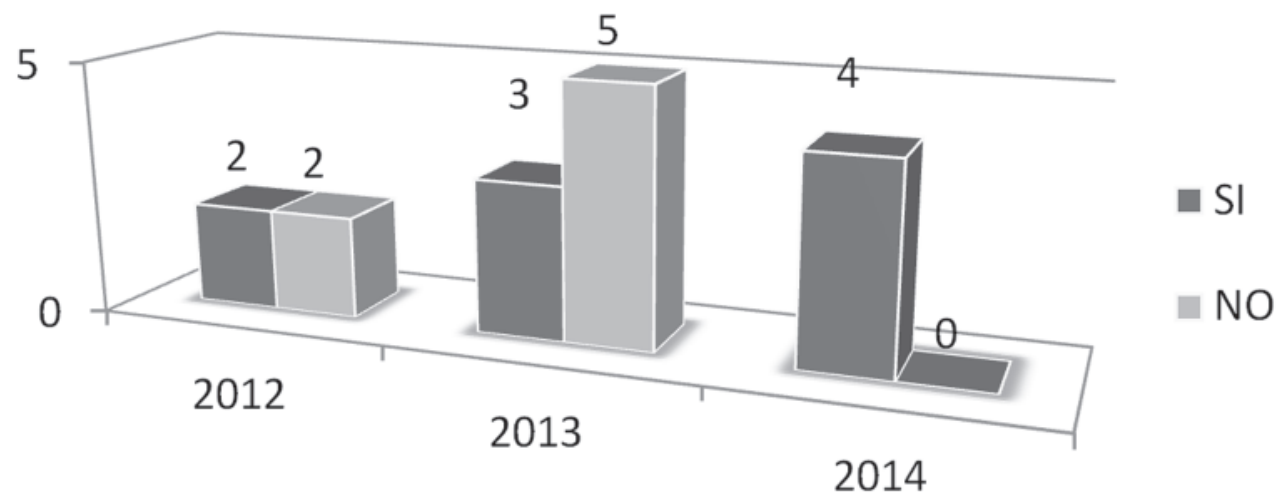

Gráfica 22. Balance de beneficios judiciales concedidos por año.

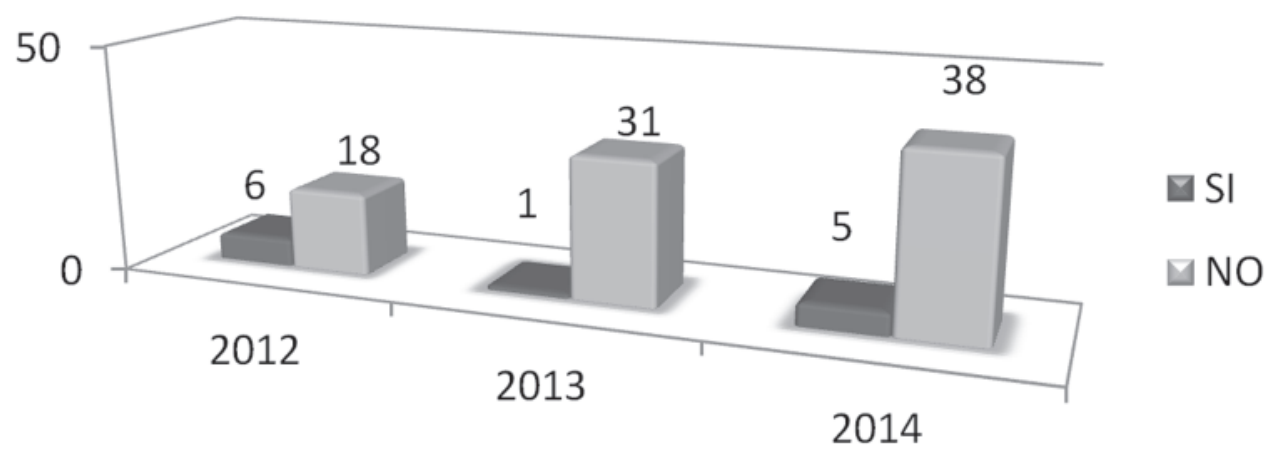


Gráfica 23. Motivos de la negación del beneficio solicitado.

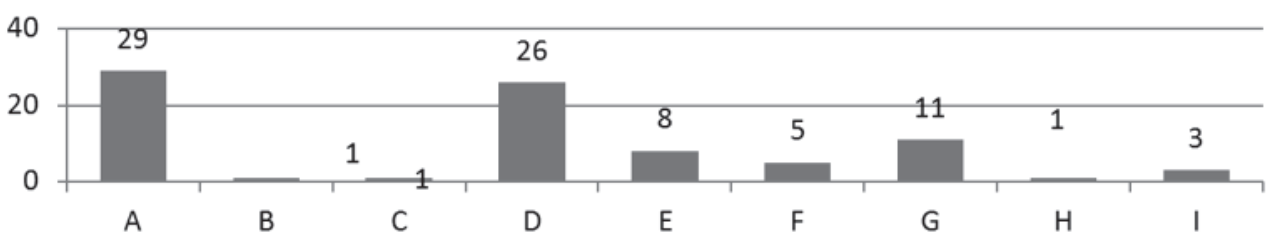

las razones; h). Falta de legitimidad en la causa; i). Reincidencia.

El motivo por el cual más se niegan las solicitudes de beneficios es indudablemente por la modalidad de la conducta, es decir, el delito por el cual se le había condenado estaba excluido de los que podían pedir algún beneficio; sin embargo, llama la atención que pese a que existen delitos que no están exentos, es recurrente por parte de los jueces, negarlos por un aspecto subjetivo, determinado por la modalidad de la conducta, configurada al momento de la comisión del delito. Este aspecto, que es el más reiterativo, se traduce en que el Juez, al momento de apreciar la concesión del beneficio, valora y estima nuevamente la conducta por la cual precisamente fue condenado, reviviendo la valoración y su grado de afectación, perdiendo de vista el proceso de tratamiento penitenciario, que el mismo Estado dispone para el recluso. Circunstancia que incluso eventualmente podría afectar garantías fundamentales, como quiera que los jueces al tomar la decisión de otorgar o no el beneficio, nuevamente fallan con base en una conducta por la cual el solicitante ya fue condenado.

De igual manera, uno de los motivos por los cuales se niegan las solicitudes, es por no cumplirse el total de requisitos exigidos para acceder a ellos, lo que evidencia la falta conocimiento del tema por parte de los reclusos. Así mismo, es usual que se nieguen los beneficios aduciendo falta de tratamiento penitenciario pese a cumplir con todos los requisitos objetivos exigidos para acceder a ello.

En el presente apartado, la investigación nos conduce a reflexionar sobre los aspectos subjetivos que la norma establece para el otorgamiento de los beneficios, que podrían aparentemente erigirse como una barrera edificada sobre la irresponsabilidad estatal en la divulgación de los beneficios, pero lo más grave, en la carencia de una política criminal que articule claras estrategias de resocialización y prevención del delito, pensada desde la óptica del respecto de la dignidad de la persona humana.

Igualmente es de suma relevancia aclarar que algunos beneficios han sido concedidos, pero el pago de la multa o la reparación integral a la víctima les ha impedido disfrutarlo; en el caso de la libertad condicional y prisión domiciliaria, por la Ley 1709 de 2014, se está concediendo con la condición de prestar una caución para garantizar distintas situaciones, pero, denuncian los reclusos que en la ciudad de Neiva la mayoría de aseguradoras no las están concediendo especialmente por la reincidencia. Los jueces de ejecución fueron consultados también sobre este punto, quienes manifestaron que esas son políticas de las empresas. Además el recluso debe tomar autorresponsabilidad de su comportamiento, y las victimas tienen derecho a su reparación (...). El papel del juez en este caso solo se limitaría a otorgar reducciones, pero lastimosamente también son pocos quienes lo solicitan.

Además, se pudo advertir que el desconocimiento de las razones o fundamentos de la negación se debe a que poseen pocos conocimientos jurídicos, no muestran interés por conocer las razones de la negación o porque en ningún momento llega a sus manos la decisión del Juez de Ejecución.

Balance de los beneficios administrativos y judiciales concedidos por año en cada juzgado de ejecución de penas de la ciudad de Neiva

Aunque el propósito de la de investigación consistía en estudiar los años 2012 a 2014 respecto a la solicitud y concesión de los beneficios, lamentablemente no se lleva a cabo la totalidad del objeto 
planteado, puesto que el Juzgado Tercero de Ejecución de Penas y Medidas de Seguridad de Neiva, no proporcionó la información o cifras las estadísticas de los beneficios concedidos entre los años 2012 y 2014, debido a que no tenían dicha información al momento de la entrevista; los Juzgados Primero y Segundo de Ejecución de Penas, no tenían las estadísticas de los beneficios concedidos en los años 2012 y 2013 y el Juzgado Cuarto de Ejecución de Penas no tenía las estadísticas de los beneficios concedidos en el año 2012. Sin embargo se lograron obtener los siguientes datos, los cuales contrastan con la información obtenida en la encuesta realizada a los reclusos, en cuanto a los pocos beneficios conocidos y solicitados por los reclusos ante los jueces encargados. De igual manera se pudo establecer que de cada 25 autos proferidos, en promedio solo un auto que tenga respuesta negativa a la solicitud le es interpuesto el recurso de apelación respectivo.

Gráfica 24. Beneficios concedidos por el juzgado primero de ejecución de penas y medidas de seguridad de Neiva, 2014:
En lo corrido del año 2014, de 74 solicitudes de prisión domiciliaria se concedieron 69 solicitudes y se negaron 5 , lo que permite inferir que la reforma penitenciaria que flexibilizó los requisitos y la vez redujo aquellos de índole subjetiva, ha funcionado, ha sido efectiva en relación con la cantidad de personas que han podido acceder a ellas.

Por el contrario, en tratándose de la libertad condicional, el panorama varia en el sentido que ha sido alto el número de solicitudes de este beneficio que han sido negadas, de 85 solicitadas sólo 10 se concedieron. Por otro lado, ha sido semejante el número de solicitudes de suspensión condicional negadas y concedidas, es decir, no ha habido variación significante en el otorgamiento de aquel beneficio, tenemos entonces que, de 11 solicitudes, 5 se concedieron y 6 se negaron.

Gráfica 25. Beneficios concedidos en el Juzgado Segundo de Ejecución de Penas y Medidas de Seguridad de Neiva, en lo que va del año 2014:

En el Juzgado segundo de Ejecución de Penas y Medidas de Seguridad, durante los meses de

Gráfica 24.

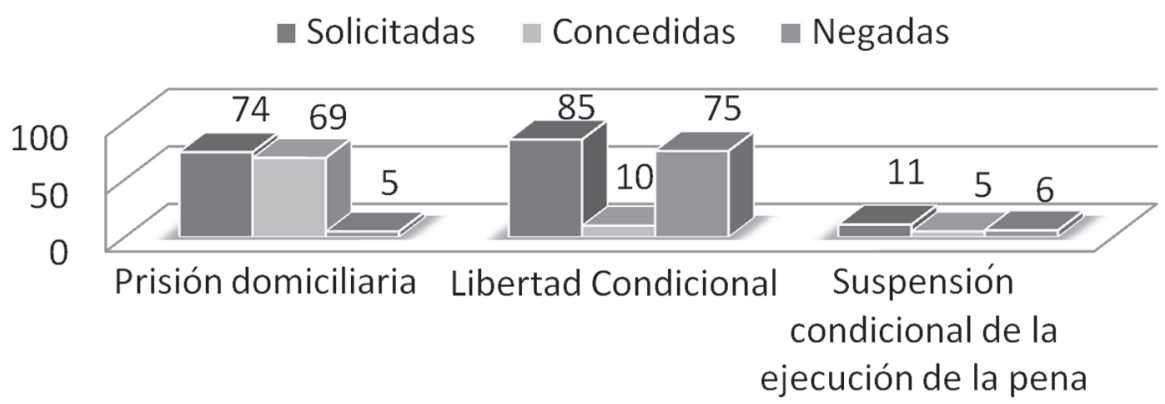

Gráfica 25.

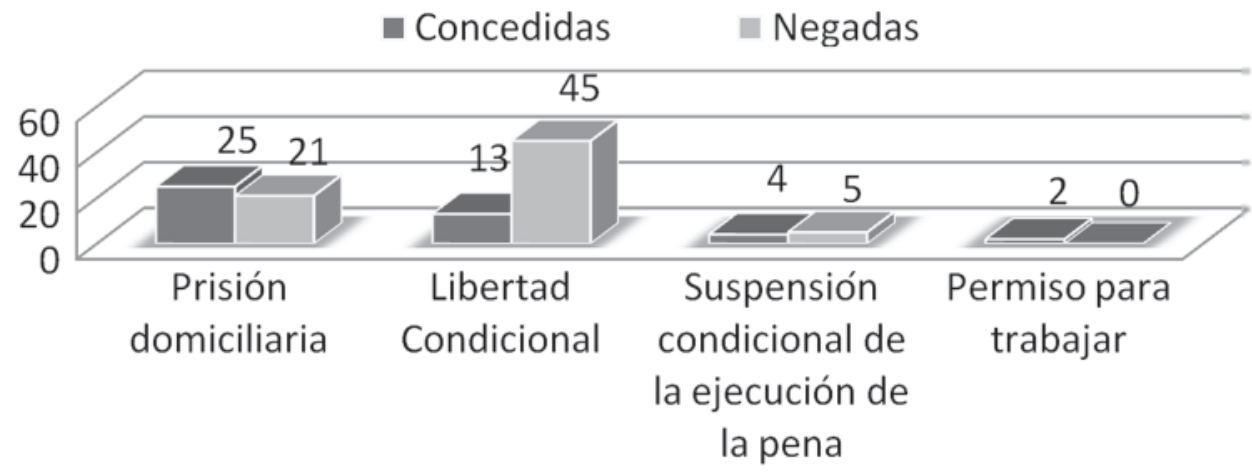


febrero y marzo del año 2014 se otorgaron en cuanto a Prisión Domiciliaria: 12 y 13 respectivamente para un total de 25 concedidas.

Por otro lado, en lo atinente a la libertad condicional, se evidenció que en el mes de enero se otorgó una, en el mes de febrero 6 y en el mes de marzo 6 para un total de 13 concedidas. Pero fueron negadas un total de 45. En tratándose de la suspensión condicional en la ejecución de la pena, de 9 solicitadas han sido concedidas 4 y negadas 5 . Igualmente puede evidenciarse que el beneficio administrativo, poco conocido, de Permiso para trabajar, tan sólo tuvo dos solicitudes.

Todo lo dicho, permite concluir que existe una gran diferencia entre la efectividad o eficacia de los administrativos establecidos frente a la aplicación los beneficios judiciales o llamados Subrogados Penales, consagrados en la Ley 599 de 2000, Código Penal vigente.

Gráficas 26 y 27. Beneficios concedidos en el juzgado cuarto de ejecución de penas y medidas de seguridad de Neiva, en el transcurso del año 2013 y 2014.

\section{Gráfica 26.}

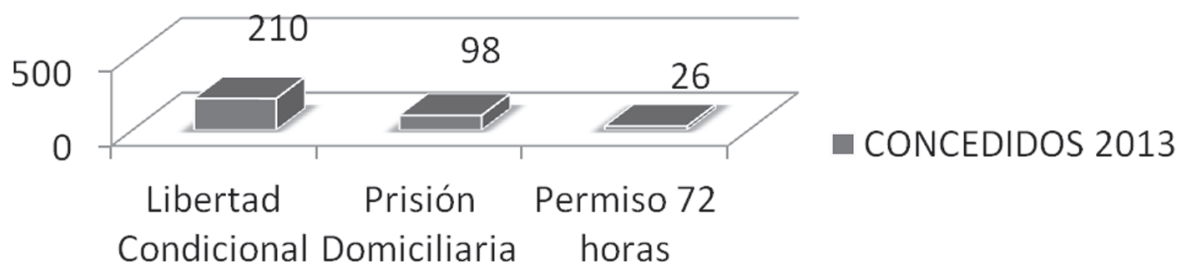

\section{Gráfica 27.}

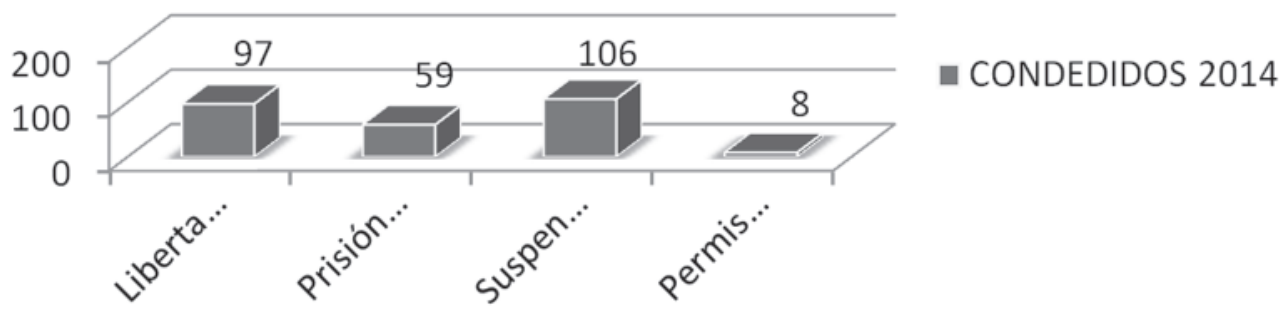

\section{CONCLUSIONES}

Existe un desconocimiento de los reclusos frente a qué y cuáles son los beneficios administrativos y judiciales, situación que se evidencia en la falta de un programa de divulgación y capacitación de los reclusos en la materia, así mismo existe una clara tendencia por parte de los Jueces de Ejecución de Penas dirigida a negar sistemáticamente las solicitudes de beneficios, basados principalmente en el aspecto subjetivo.

Conforme a las variables, se está recurriendo principalmente a los beneficios de prisión domiciliaria, permiso de hasta 72 horas y libertad condicional.
Los motivos por los cuales se han negado solicitudes de beneficios han consistido entre otros por: i). Modalidad de la conducta; ii). La falta de tratamiento penitenciario; iii). Falta de cumplimiento de requisitos exigidos; iv). Reincidencia, los cuales son tenidos en cuenta por los jueces en el aspecto subjetivo.

Resultado de lo anterior, se puede evidenciar que el fenómeno del hacinamiento no se intervino apropiadamente con la reforma de la ley 1709 de 2014, ni se abordó el aspecto del tratamiento penitenciario.

Con base en lo anterior, el semillero diseñará unos lineamientos basados en los resultados de la investigación, enfocados principalmente a: 
- Que el Ministerio de Justicia adopte un programa de divulgación y capacitación de los beneficios administrativos y judiciales.

- La formulación una reforma a los beneficios, que propone incluso derogar el aspecto subjetivo, por considerarlo peligrosista.

- Elevar al Gobierno la necesidad de la perentoria adopción de una política criminal, que corresponda con la naturaleza de un sistema que se inspire en la prevención del delito, el tratamiento penitenciario y resocialización, a través de un programa de trabajo interdisciplinario con estrategias de intervención sicosocial efectivas basadas en el desarrollo humano.

De igual manera, el semillero propone como estrategias a corto plazo:

- Implementar un programa de capacitación en beneficios administrativos y judiciales dirigido a los Reclusos del INPEC Neiva.

\section{REFERENCIAS BIBLIOGRÁFICAS}

- Castro, N. (2009). Realidad penitenciaria y derecho humanos (Tesis de maestría) Universidad internacional de Andalucía, España.

- Código penitenciario y carcelario (ley 65 1993). Recuperado de http:// http://www.alcaldia bogota. gov.co/sisjur/normas/Norma1.jsp?i= 9210

- Código penal (Ley 599 de 2000). Recuperado de http://www.secretariasenado.gov.co/senado/ basedoc/ley_0599_2000.html.

- Código de procedimiento Penal (Ley 906 de 2004). Recuperado de http://www.alcaldia bogota.gov.co/sisjur/normas/Norma1.jsp?i= 14787.

- CConst, T-153/1998, E. Cifuentes. Recuperado de http://www.corteconstitucional.gov.co/relatoria /1998/T-153-98.htm.
- CConst, T-318/1995, A. Martínez. Recuperado de hhttp://www.corteconstitucional.gov.co/relatoria/ 1995/C-318-95.htm

- CConst, T-1030/2003, C. Vargas. Recuperado de http://www.corteconstitucional.gov.co/relatoria/ 2003/T-1030-03.htm.

- Defensoría del pueblo y oficina del alto comisionado para los derechos humanos. Derecho de las personas privadas de la libertad. Manual para su vigilancia y defensa: Suplemento: Protección constitucional y derechos fundamentales de las personas privadas de libertad. (2006). Bogotá, Colombia: Nueva Legislación Ltda.

- $\quad$ Ministerio del interior y de justicia. Decreto 232 de 2 de febrero de 1998. Recuperado de http:// www.hchr.org.co/documentoseinformes/documentos/carceles/4_Nacionales/1_Normas_ basicas/3_Reglamentacion_modifa_regimen _carcel/ Reglamentacion.htm

- Oficina en Colombia del alto comisionado para los derechos humanos. (2006). Personas privadas de la libertad. Jurisprudencia y Doctrina. Bogotá, Colombia.

- Oficina del alto comisionado de las naciones unidas para los derechos humanos. (1955) Reglas mínimas para el tratamiento de los reclusos. Recuperado de http://www2.ohchr.org/spanish/ law/reclusos.htm

- Ley 1709 de 2014. Por medio de la cual se reforman algunos artículos de la Ley 65 de 1993, de la Ley 599 de 2000, de la Ley 55 de 1985 y se dictan otras disposiciones Recuperado de http://www.alcaldiabogota.gov.co/sisjur/normas/ Norma1.jsp?i=56484.

- L. 733/2002. Por medio de la cual se dictan medidas tendientes a erradicar los delitos de secuestro, terrorismo y extorsión, y se expiden otras disposiciones. Recuperado de http:// www.alcaldiabogota.gov.co/sisjur/normas/ Norma1.jsp?i=22772. 